\title{
The Evolution of the Style of Chinese Documentary Photography
}

\author{
Xiaozhou Li \\ School of Art \& Design \\ Xi'an University of Technology \\ Xi'an, China
}

\begin{abstract}
Documentary photography began to appear in China from 1920s to 1930s, but developed relatively slow and hard due to social instability and political influence. At each period, unfavorable factors for documentary photographic language system will occur, so it really began to move forward until the late 1980s and early 1990s. After entering the 21st century, under the social background of rapid economic development, when documentary photography maintains its independence, its performance and language system have undergone changes.
\end{abstract}

Keywords-documentary photography; performance style; language system

\section{INTRODUCTION}

Recording is the inherent feature of photography, which can be used to record the actual scene through optical and chemical means. In the development course of photography, documentary photography gradually formed a language system for recording the living conditions of human beings as well as social state, which in turn plays the role of influencing social development. Documentary photography developed slowly in China due to social turmoil and political reasons. This situation lasted until the 1980s when the relatively enlightened economic and political development provides stable development foundation for documentary photography. Some outstanding documentary photography appeared during this period, writing a valuable piece of Chinese photography in the history of world photography. In the 21 st century, the diversification of values is becoming more and more obvious, and the fast-growing society is dazzling. Sustained rapid economic growth, industrialization and urbanization make people see the scene of construction everywhere. Under such a social background, the performance style of documentary photography also changes.

\section{DEVELOPMENT FORM OF DOCUMENTARY PHOTOGRAPHY IN CHINA}

Photography came to China in the 1840 s with the outbreak of the Opium War. At the end of the feudal society, the invasion of Western powers and the backwardness of the feudal dynasty made the masses have no means to live, let alone talking about the development of culture and the arts. When reviewing the history of photography, we can often see photograph about backward and barren images of China in the mid-to-late 18th century, which are mostly taken by foreign photographers, and these images can also be summarized as part of the history of colonial plunder [1].

\section{A. Budding Period of Chinese Documentary Photography}

In the 1930s, influenced by the New Culture Movement, photography developed in China. However, the tradition of literati and officialdom in China did not disappeared in this period, and the content of photography still stayed in the state of enjoying the air and the moon and beautiful scene. Documentary photography did not show up prominently because of social turmoil. In this period, the domestic photographers who have made significant contributions to the development of documentary photography in China include Sha Fei as in "Fig. 1", Zhang Yinquan and Zhuang Xueben in Fig. 2". They mainly focus on the general public and give play to the essence of the record of photography to leave many precious images for China at the time.

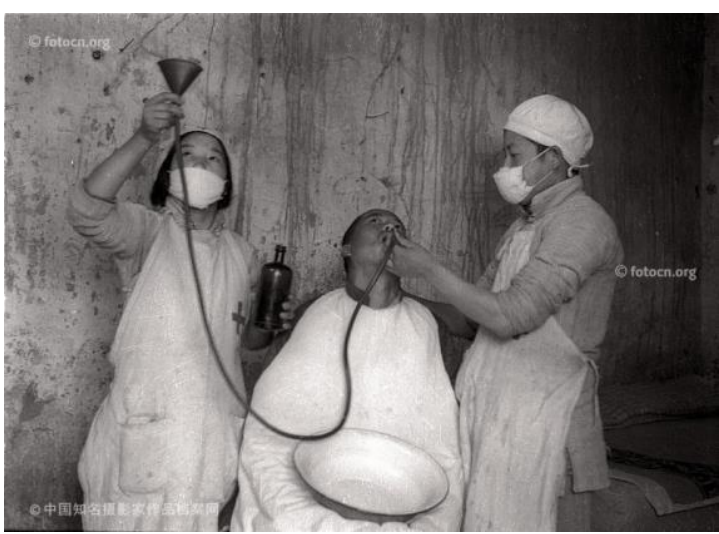

Fig. 1. Photography/ Sha Fei. 


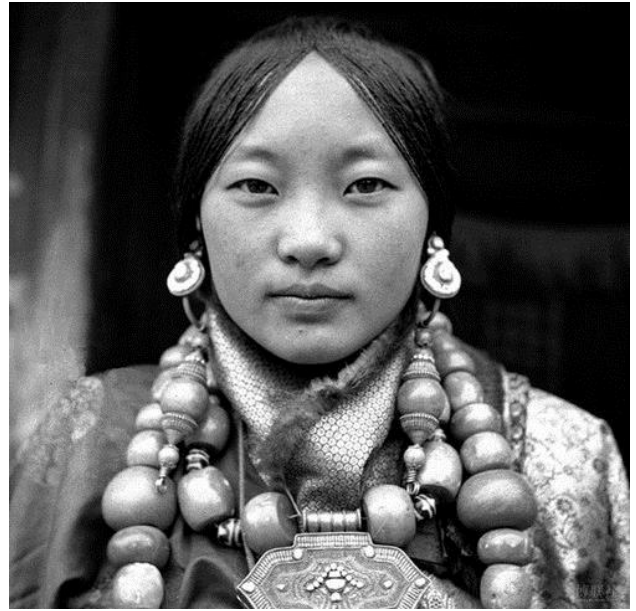

Fig. 2. Photography/ Zhuang Xueben.

As for shooting method, they directly, objectively and systematically collect images based on the harmonious contact of the subjects. These photos ensure the true nature and at the same time they sweep away the dull and silly impression of the West on oriental images.

\section{B. Stagnation of Chinese Documentary Photography}

The founding of new China did not bring a turning point for the development of photography, but instead made photography into a vicious circle. The photography in this era has become the main tool for political services, and the performance content are mostly themed with "tall, big and comprehensive, and red, bright and light". This situation reached the peak during the Cultural Revolution [2]. During this period, in the expressive subject matter and rules of documentary photography, a serious left-leaning state appeared, so that the subject matter can only show bright things. The rules can only "agitate" and praise, and cannot expose or criticize as in "Fig. 3" and "Fig. 4". This situation was not changed until the holding of "April Photography salon" in 1976.

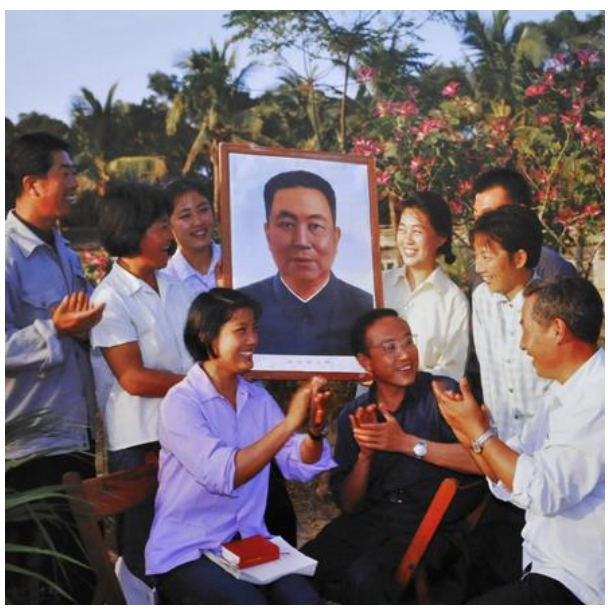

Fig. 3. Photography $1 /$ Zhu Xianmin.

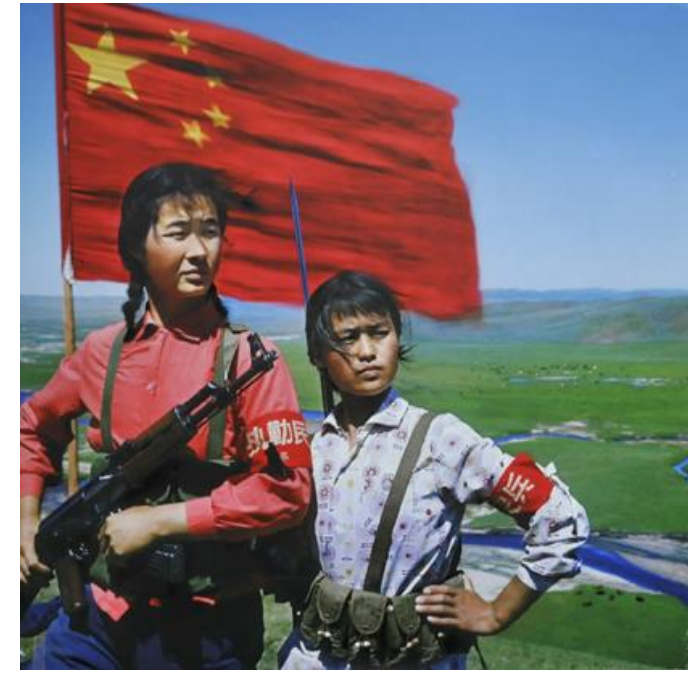

Fig. 4. Photography 2/ Zhu Xianmin.

The sponsors of April Photography salon were mainly a group of young people who volunteered to photograph the masses mourning Zhou Enlai at the Tiananmen Square in 1976. Two years later, the Tiananmen Square incident was redressed. In 1979, this group of young people held a "nature, society, and human" photo exhibition in April in the same year and the following year [3]. Most of the works in the exhibition are based on realism. However, the exploration is still under the aesthetic category of truth, kindness and beauty, but did not form the language system of documentary photography. The real development of documentary photography in China was realized in the late 1980 s to early 1990 s.

\section{A Real Sense of Development of Chinese Documentary Photography}

Reform and opening up were the real liberation of China. During this period, the economy was active and the foreign exchange increased. The western photographic theory system gradually appeared in China. During this period, a number of theorists such as Wang Huimin, Huang Shaohua and Xie Hanjun emerged, promoting the development of documentary photography. With the support of the theoretical system, photography can rise to the academic level. Since then, with the gradual improvement of understanding and practice, the work of some photographers began to gradually be recognized and accepted by the public. Photographer such as Zhu Xianmin's "people of Yellow River Central Plain", arduous journey, and the exhibition of "Shaanxi group" represented by Hu Wugong, Hou Dengke, Shi Baoqian, Qiu Xiaoming and Pan Ke, Beihe League in Shanghai gradually became successful. After the 1990s, some scholars who returned from overseas, such as Zeng Huang, Wang Rui, and Gu Zheng and so on brought the foreign photography system to China. Some theorists such as Li Mei, Yang Xiaoyan, Liu Shuyong, Bao Kun, Sun Jingtao, and Lin Lu deeply study and develop the photographic theory system in different ways and different positions [4]. After that, the documentary photography in China entered the peak period of creation, and many photographers' works 
appeared in the public view, including Xie Hailong's Hope Project, Chen Jin's Sichuan Tea Shop, Zhang Xinmin's Liukeng, Jiang Jian's Master, Hu Wugong, Hou Dengke, and Qiu Xiaoming's Quartet City, Yang Yankang's "Quadrangle", Lin Yonghui's "northeasterner", Yang Yankang's "Rural Catholicism", Wang Zheng's "Xihaigu region", Zhao Tielin's "Alternative Life", and Li Lang's "Yi people in Liangshan" and so on. These works not only enable us to see the vigorous development of documentary photography, but also reflect the diversification of social values and the enhancement of individual consciousness from different angles. The privatization of documentary photography began to develop in the late 1990s, which attempted to redefine documentary photography. Such as Mo Yi's "What the Dog Saw", Liu Zheng's "countrymen" series allows us to see another way of development of record photography.

\section{THE EVOLUTION OF STYLE OF DOCUMENTARY PHOTOGRAPHY IN CONTEMPORARY ERA}

\section{A. Inheritance and Development of Documentary Photography}

After entering the 21st century, Chinese documentary photography still develops in an orderly manner and its performance style is increasingly diversified. Some Mesozoic photographers still maintain a good creation state and integrate into new performance contexts by using more mature language systems, such as Yang Yankang's "Tibetan Buddhism", Lu Ning's "usual", Peng Xiangjie's "Three religions and nine streams", Liu Lihong's "Land", A Yin's "Mongolian", and Yan Changjiang's "The Last Three Gorges" and so on. Through these Mesozoic works, we can not only see the more traditional documentary photography, but also see the change of documentary photography in the new era.

In the 21 st century, the new generations of photographers deliver their own social awareness and vent of emotions in works through the way of record, such as Ta Ke's "Study on poem, mountain and river", Luo Dan's "318 State Road", Chen Zhe's "The Enduring Series", Zhang Xiao's "Coastline," in "Fig. 5" Yan Ming's "My Wharf", Ri Yue's "New Human Festival", Su Sheng's "Chinese Child", Sun Yanchu's "Indulgence Here" and so on. The viewpoint of the new generation documentary photography is more personalized. Compared with documentary photography in the 1980s and 1990s, it lacks a sense of social responsibility and has more agitation and restlessness in the current society, which exactly has direct relationship with the current social situation [5].

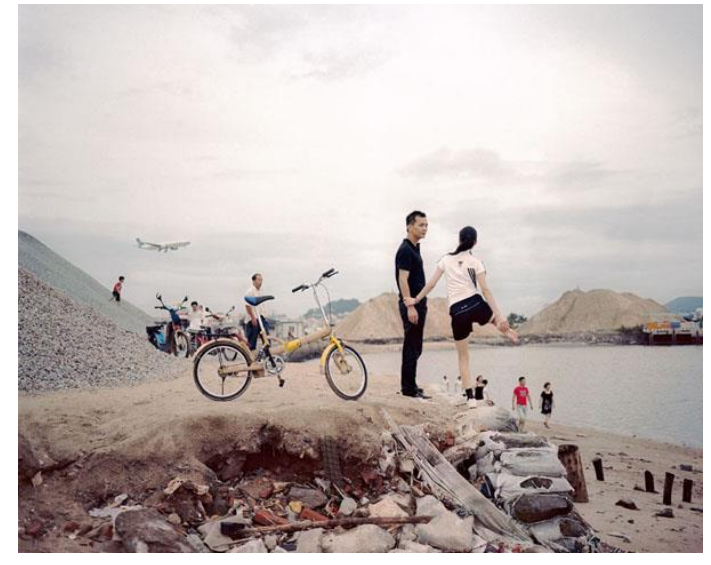

Fig. 5. "Coastline" Photography / Zhang Xiao.

\section{B. The Rise of Landscape in Documentary Photography}

Landscape photography is also known as "deadpan" photography, of which the concept dates back to German neo-realism of the 1930s, the "Dusseldorf School" derived in the 1960s, and the two major exhibitions in the American photography circle in the 1970s: "contemporary photographers: Towards Social Landscape" and "New Terrain: Artificially Changed Landscape Pictures." With continuous summary and questioning, landscape photography has gradually become an important type active in contemporary Western photography [6]. It refers to a type of photography that appears in the consumer society and urbanization process under the guidance of a calm, rational and relatively objective way of viewing and takes the "artificial landscape" as the subject. As shown in "Fig. 6", through these "landscape", it is full of photographer's questioning and criticism to the reality. At the moment, some photographers use the way of record to look at the earthshaking society where we are both familiar and unfamiliar.

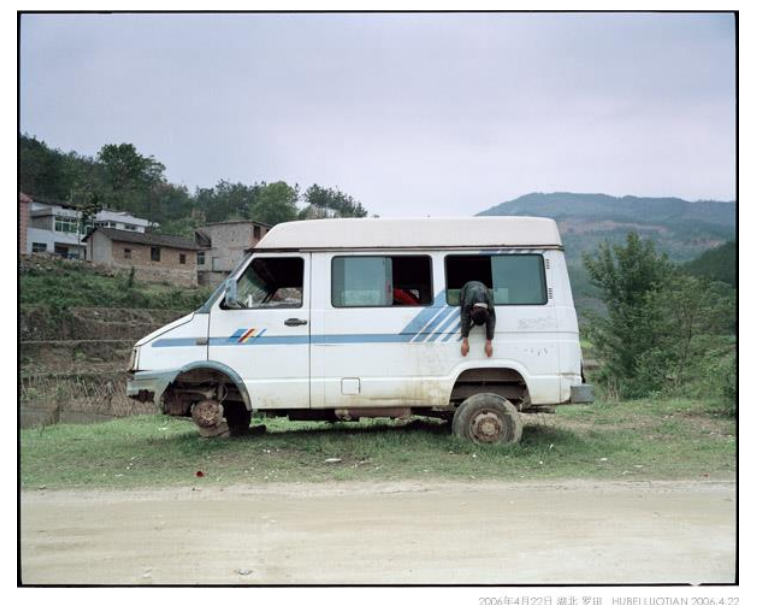

Fig. 6. "318 national highway" photography / Luo Dan.

The objective social landscape photography evolved from the style of landscape photography offers a way of presentation. This objective approach avoids sensationalism and changes the direction of traditional landscape photography only paying attention to aesthetics instead of the 
social and cultural connotation of landscape. Objective social landscape photography is an attitude as well as a position.

\section{CONCLUSION}

Development of photography is inseparable from the communication. With the idea of holding photographic exhibitions abroad, large-scale photographic exhibitions and photography festivals frequently appear in China, such as the Pingyao Photographic Festival, Lianzhou Photographic Festival, Yunnan Dali Photographic Festival, and Lishui Photo Festival. In addition, a number of private photography awards have also contributed to the development of photography, such as the Hou Dengke Documentary Photography Award and the three shadows Photography Award. Second, network is the main carrier of communication in this era and some photography websites gradually move towards specialization and academicization. In the Mainland, there are many influential websites, such as Limitless pics network, Artron Network, New Photography Network, and Fengniao Network. All of these factors provide a good platform for the communication of documentary photography. Documentary photography will enter a period of multiple developments. The self-awareness of basing on individual and facing the society of photographers will become stronger and their contribution to the Chinese society and culture will be substantive.

\section{REFERENCES}

[1] Li Wenfang. World Photography History. Shenyang: Liaoning Fine Arts Publishing House, 2007.08.

[2] Yi Ke. The history of photography. Chongqing: Chongqing Publishing House, 2008.9.

[3] Li Lu. intellectual history of photography. Hangzhou: Zhejiang photography press, 2008. 03.

[4] Sun Jingtao. Style and Exploration of Documentary Photography. Ji Nan: Shandong pictorial publishing house. 2004. 06.

[5] Su Zhigang. Dialogue between the mirror. Changchun: Jilin photography publishing house, 2003. 06.

[6] Gu Zheng. There is no truth behind the reality. Beijing: China workers publishing house, 2002.05. 